\title{
Site Screening
}

National Cancer Institute

\section{Source}

National Cancer Institute. Site Screening. NCI Thesaurus. Code C142689.

The process by which a location is monitored and assessed to ensure that the venue and staff are appropriate for clinical study work. 